\title{
El director productor y la dramaturgia como acontecimiento: el caso de Sergio Boris
}

\author{
Martín Gonzalo Rodríguez \\ Instituto de Investigación en Teatro-UNA/ CONICET, Argentina \\ martinrodriguezuna@gmail.com
}

Fecha de recepción: 24/02/2021. Fecha de aceptación: 20/03/2021.

El objetivo de este artículo es abordar la categoría director productor y describir sus tareas en relación con su otro necesario, el actor productor, para luego centrarse en el caso puntual de Sergio Boris y en las peculiaridades de su poética.

PALABRAS CLAVE: DIRECTOR PRODUCTOR, ACTOR PRODUCTOR, SERGIO BORIS, POÉTICA.

\section{The Director - Producer and Dramaturgy as an Event: the Case of Sergio Boris}

The aim of this article is to approach to the category of director-producer and describe his tasks in relation to his necessary other, the actor-producer, and then focus on the specific case of Sergio Boris and the peculiarities of his poetics.

KEYWORDS: DIRECTOR-PRODUCER, ACTOR-PRODUCER, SERGIO BORIS, POETIC.

\section{El actor productor}

Para dar inicio a este trabajo resulta imprescindible, en primer lugar, establecer la distinción entre actores creadores y actores productores, ya que cada una de estas figuras está estrechamente asociada a dos modos de concebir la dirección escénica que encarnan en las figuras del director creador y el director productor. No podemos asegurar que las figuras del director creador y del director productor agoten el panorama de la dirección escénica en la Argentina, pero sí delimitan dos modos de concebir la escena y el lugar del actor.

Comencemos, entonces, por definir actor creador y actor productor. Partimos de la distinción entre estas dos formas de actuación que desarrollamos junto con Sandra Ferreyra a partir de la distinción entre autores creadores y productores que señala Benjamin en su artículo "El actor como productor" (2002). Extrapolando conceptos, 
decimos que actor creador es aquel que cree estar en posesión de un "aparato" y no percibe que en realidad éste lo posee a él. Suele corresponderse con lo que Benjamin (2002) denomina "modo espiritual" que es aquel por medio del cual los artistas experimentan su solidaridad con "la causa del pueblo" según su propio ánimo: en estos casos, por muy progresista que parezca su arte, siempre tendrá un matiz conservador, ya que elude toda referencia al lugar que ocupa dentro de los medios de producción y, por lo tanto, es incapaz de transformarlos. En este caso, los medios transforman a los artistas que no pueden más que reproducir lógicas exteriores a ellos, interiorizarlas y dejar que se impongan a sus "buenas intenciones".

Sin que esto sea definitivo, creemos posible encontrar dos variantes en el actor creador: la variante empática y la variante satírica, que en sus diversas formas siempre involucran el juicio. El juicio es su fundamento y la sustancia que hace posible la subordinación de cada una de estas variantes a la lógica de los medios de producción, a partir de instancias jerárquicas que parten de la superioridad de lo Uno sobre el Ser y determinan un funcionamiento vertical que necesita de ideas como el Bien o la Verdad para ponerse en movimiento. ${ }^{2}$

A diferencia del actor creador, el actor productor interviene en el proceso de producción de sentido sabiendo que el aparato está siempre ahí para devolverlo al lugar del que nunca debió haber salido (el sentido común actoral o lo políticamente correcto cuyo principio es el juicio). Puede producir ficción sin necesidad de un texto previo pero, aún en caso de que lo haya, jamás se subordina a sus contenidos: conoce su lugar dentro de los medios de producción y es capaz de manipularlos y ponerlos al servicio de lo que Alejandro Catalán (2002) llama "producción de sentido actoral".

Sin descartar el carácter innovador de los actores de los ochenta, pensamos que es posible establecer una genealogía de la producción de sentido actoral cuya procedencia se encuentra en el actor popular que, a diferencia del actor culto, produce sentidos específicamente actorales y pone en primer plano las pasiones al tiempo que

1. La idea de "aparato" es introducida por el propio Benjamin en su artículo y su sentido no es aclarado. En nuestro trabajo, entendemos por aparato todo aquello que interviene en los procesos de producción teatral. Involucra tanto aspectos de distinto orden que van desde la escenografía, el vestuario o la forma de la sala hasta las formas teatrales y los estilos de actuación y aún concepciones de la existencia que exceden lo teatral. Es en este sentido que decimos que quienes intervienen en estos procesos pueden dominar este "aparato" o ser dominados por él.

2. Para este desarrollo, partimos de la distinción entre sátira y ética que desarrolla Spinoza y retoma Deleuze (2008: 89-93) en sus clases. Para pensar estas variantes del actor creador, bastaría con tomar ejemplos varios que pueden ir de la empleada pública interpretada en televisión por Gasalla (mirada condenatoria de no pocas implicancias políticas) hasta obras como Terrenal (2014) escrita y dirigida por Mauricio Kartun, en la que es posible ver cómo en los actores se conjugan la sátira y la empatía en función de una lógica que es exterior al campo específico de la actuación, de una moral reforzada por la mirada final de Tatita. Se trata de ejemplos ajenos a nuestro corpus pero clarificadores y necesarios. Podemos observar cómo funciona este punto en la trayectoria de un actor emblemático como es el de Luis Brandoni: formado inicialmente en el Conservatorio Nacional en las técnicas de la llamada dicción interpretativa o declamación, logra notables desempeños "realistas" con autores, directores y autores de esa poética en películas como Tute cabrero (Juan José Jusid, 1968), basada en la obra homónima de Roberto Cossa. Sin haber tenido un tránsito formativo dentro de las técnicas desarrolladas en el país a partir de la recepción productiva del método Strasberg, logra no obstante destacadas actuaciones introspectivas junto con actores formados en esas técnicas. Toda esta primera etapa puede incluirse dentro de la variante empática. Sin abandonar por completo esta variante, a partir de la década del setenta comienza a desarrollar actuaciones dentro de la variante satírica, en obras de autores como Roberto Cossa y Oscar Viale y Jacobo Langsner entre las que se destaca La Nona (1977), de Cossa con dirección de Carlos Gandolfo. Sin entrar en detalles, vemos que tanto en una u otra variante la actuación se centra en el juicio: hay, en el primer caso, una mirada que acompaña al personaje (lo juzga y lo comprende pero no lo aprueba) y, en el segundo caso, una mirada que rechaza (juzga y condena desde la comicidad). En ambos casos lo hace a partir de criterios exteriores (por lo general morales) que pretenden aleccionar, mostrar "lo que está bien y lo que está mal”. 
se aleja del llamado "decoro interpretativo". Creemos que el establecimiento de una genealogía de la producción de sentido actoral es indispensable para poder elaborar un mapa descriptivo y crítico del teatro que se hace en Buenos Aires en nuestros días. Para empezar a acercarnos al actor productor, deberíamos realizar una genealogía del actor productor que se inicia a principios del siglo XIX con actores populares como Luis Ambrosio Morante, continúa con los Podestá, Florencio Parravicini, Luis Arata, Olinda Bozán, Luis Sandrini y Pepe Arias hasta llegar a Alberto Olmedo. Esta genealogía se extiende de manera discontinua (pero no por ello menos productiva) en la irreverencia de actores emergentes de la década del ochenta como Alejandro Urdapilleta, y tiene un punto de viraje en el "devenir obra" que se produce fundamentalmente con la irrupción de dos directores productores (los primeros en su especie): Pompeyo Audivert y Ricardo Bartis y el estreno de Postales argentinas en 1988. Son ellos los que abren el campo de la dirección concebida como producción en relación con ese tipo particular de actor que es el actor productor.

El actor productor que emerge en los ochenta cita al actor popular (se cita con él) en la rutina. La rutina es, sin dudas, la forma más elemental del teatro, ya que solo requiere de una serie de pautas o de acuerdos de un actor con otro actor o consigo mismo en función de un espectador. Entendemos por rutina a una secuencia o partitura de acciones más o menos pautadas que se realizan frente a un público. Parte de la idea de que la actuación precede a la narración y se impone a ella: aun cuando se trabaje con materiales preexistentes (novelas, cuentos, obras dramáticas, noticias periodísticas, comportamientos sociales, personajes conocidos, otras formas actorales o cualquier otro material pasible de ser utilizado), estos se ponen al servicio del actor que arma su rutina por fuera de la lógica inmanente de cada uno de estos materiales.

Ciertas formas del teatro del absurdo han capturado parcialmente la forma rutina para exhibirla como puro mecanismo, vaciándola de uno de sus aspectos fundamentales que es la producción de sentido actoral y obviando que es siempre una forma de vínculo, ya sea vínculo de dos o más actores, entre un actor y un objeto o un sistema de objetos o entre un actor y su público. Ese vínculo parte de la capacidad de asociar cosas que aparecen como disociadas y viceversa y siempre involucra un aspecto poco tenido en cuenta a la hora de pensar el actor popular: el afecto, entendido como una pasión del ánimo cercana al amor o al cariño pero también como término próximo a la idea de afectar. Respecto del segundo de estos sentidos, resaltamos la capacidad de afectar y dejarse afectar por un otro, ya sea persona u objeto: quizás los mejores actores productores sean aquellos que logran abrirse al juego con los otros actores pero también al juego con los objetos.

Se trata de ver los modos en que desde la rutina se encuentran afinidades entre palabras, gestos y objetos diversos. Lejos de ser una forma fija, la rutina es abierta y proteica: se va armando en los ensayos y a lo largo de las funciones, permite supresiones, inversiones, cambios y agregados, habilita el montaje. Puede involucrar a la palabra pero también prescindir de ella; ni siquiera requiere de una forma narrativa clásica de introducción, nudo y desenlace. En última instancia, es puro trazo y es este aspecto el que recupera y reformula el actor productor que emerge en la década del ochenta.

\section{El director productor y sus tareas}

Frente a estas singularidades, el director que trabaja con los actores en tanto productores tiene al menos tres tareas:

1) Generar un campo imaginario en común o facilitar su generación, por ejemplo, a partir de la lectura de textos dramáticos, narrativos o ensayísticos (pero también de 
la lectura de textos sociales) de los cuales los actores puedan extraer tanto situaciones y fragmentos textuales disponibles para ser utilizados aleatoriamente como tonos, ritmos, movimientos, gestos, vínculos con los otros actores, etc.

En el teatro de Ricardo Bartis, Pompeyo Audivert, Bernardo Cappa o Eugenio Soto, por citar algunos ejemplos, se ponen en relación un conjunto de textos literarios que configuran verdaderos cánones personales (Shakesperare, Dostoievski, Discépolo, Sánchez, Arlt, Borges, Lamborghini y Echeverría, entre otros) pero también estructuras míticas como el tango, el fútbol o los discursos de Perón y Evita y textos sociales con un sistema de objetos (algunos reconocibles y asociados a mitos nacionales y otros que generan una sensación de extrañeza, de distancia con el pasado del cual fueron arrancados) y con el cuerpo de los actores. La actuación opera como un espacio de asociación en el que textos y objetos son traducidos a gestos, tonos y palabras que los afirman, los niegan, los ponen en cuestión, ironizan sobre ellos. La elección no fortuita de esos textos busca poner en primer plano cuestiones centrales para pensar nuestra cultura, nuestro pasado y nuestro presente a partir de lo que Bartís llama la "movilización de fuerzas inasibles de lo real".

2) Estimular las capacidades asociativas y disociativas de los actores generando situaciones sobre las cuales "improvisar" (con todas las prevenciones que nos inspira esa palabra).

Esas situaciones muchas veces son escenificaciones de los vínculos que los actores generan entre sí a lo largo de los ensayos (celos, afinidades, conflictos, reclamos al director, ausencia de un texto definitivo, etc.). Utilizamos la palabra "improvisar" para que se comprenda con cierta facilidad a qué nos referimos; sin embargo, coincidimos con Alejandro Catalán en algo que suele repetir en clases y conversaciones: cuando un escritor comienza a escribir o un pintor empieza a pintar, no decimos que está improvisando. La idea de que el actor cuando actúa sin un texto previo o sin seguir directivas precisas de un director está "improvisando" tiene que ver con un teatro que no concibe una actuación autónoma del texto o de la dirección y, por lo tanto, no tiene en consideración la posibilidad de producir sentido ella misma (producir relato o ficción), es decir, de apropiarse de su medio de producción: la actuación misma y sus procedimientos específicos. De la misma manera que no todo escritor produce sentido cuando escribe (ya que para hacerlo debe conocer los medios de producción y ser capaz de manipularlos y transformarlos mediante la técnica), tampoco todo actor que "improvisa" lo hace realmente, ya que el que improvisa puede estar remedando un modo de producción sin conocer sus mecanismos y sin atender a las concepciones de actuación que están por debajo de esa improvisación. De hecho, el actor realista (o naturalista, como suele llamárselo) improvisa en las clases y ensayos, pero lo hace a partir de supuestos que son exteriores a la actuación y que, por lo general, tienen que ver con la psicología del personaje y el sistema de valores asociado a ella. Cuando un director de esa tendencia recurre a la improvisación en función de la creación de un personaje, le está pidiendo al actor que recupere algo que precede a la acción de improvisar. Las circunstancias dadas, el sí mágico, la memoria emotiva son técnicas que tienden a la creación de un personaje por fuera de la posibilidad que el actor tiene de producir sentido porque, en última instancia, son el "texto dramático" y el "texto espectacular" los portadores del sentido. Más allá de lo que el actor haga en sus improvisaciones, será en última instancia Chejov quien decida qué deben decir los actores o será el director quien determine cómo deben abrir una puerta Medea o Treplev.

Lo que está en juego es pensar la improvisación como creación o como producción de sentido y en este desacuerdo se pone en escena una política de la actuación que separa a actores y directores creadores (espirituales) de actores y directores productores 
(materiales). El término "improvisación" es un espacio en disputa entre dos modos de concebir la actuación y, en tal sentido, resulta ilustrativa la mención de la llamada "creación colectiva" de los sesenta y setenta. Buena parte de los detractores de la figura del actor productor dicen: "eso ya se hacía en los setenta", sin tener en cuenta que los principios que rigen uno y otro modo de concebir la improvisación son completamente diferentes.

Hemos hablado de las pasiones que intervienen en el actor productor pero aún no hemos descripto su funcionamiento escénico tal como lo habilita la dirección: las pasiones así entendidas son los modos en que los actores productores son afectados por el espacio, los objetos, los otros actores y los espectadores; ellas hacen posibles vínculos variables y contradictorios, abren el campo imaginario, habilitan tonos, gestos y actitudes singulares y permiten conectar lo que en una primera instancia parecía no estar conectado de modo alguno, afectar y dejarse afectar: en palabras de Ferreyra (2019) "asociar y disociar imágenes". Quizás los mejores actores productores sean aquellos que logran abrirse a lo otro, al juego con los otros actores pero también a la posibilidad de comunicarse con los objetos, de encontrar relaciones secretas con y entre ellos. Se trata de ver los modos en que estos actores encuentran afinidades entre palabras, gestos y objetos diversos para configurar con ellos imágenes estéticas singulares a partir de lo que Benjamin (1991) denomina "percepción de lo semejante". Para tomar un ejemplo que nos permita acercarnos a esta idea, remitimos a la escena en la que Chaplin se come un zapato cuyos cordones convierte en suculentos fideos. ${ }^{3}$ En este caso, es la acción la que produce una semejanza (cordones y fideos) y la asimila a un gesto específico: el de comer como lo hace un burgués, con todo el ceremonial y el placer que ese acto involucra. Sin embargo, la potencia de esta escena no se agota en la acción que produce la semejanza: necesita del afecto, de la profunda conexión que Chaplin establece con ese zapato y esos cordones.

Por supuesto que en el caso de Chaplin y de muchos otros actores productores no es posible hablar de dirección (en todo caso habría algo así como una auto dirección). Pero en los casos en los que interviene un director productor, éste participa de la escena "como un actor más", proponiendo acciones o textos o comentando la escena de diversos modos (haciendo sugerencias a viva voz, susurrándole palabras al oído a los actores o modificando posturas o movimientos mediante la intervención física directa). Se trata de intervenciones que redireccionan las escenas y provocan giros que reconfiguran el campo asociativo. Es importante tener en cuenta que todos los directores productores son al mismo tiempo actores productores ellos mismos: es esta una condición indispensable para la puesta en marcha de este modo de concebir la dirección escénica.

3) Recuperar las imágenes generadas y realizar un montaje con ellas a fin de producir una obra.

Esta tarea de índole dramatúrgica que se realiza en buena medida en los ensayos también requiere poner en juego capacidades asociativas y disociativas cercanas pero diversas de las de los actores. En estos casos, los directores productores escriben solos o con la colaboración de dramaturgos o asistentes de dirección que cumplen esa función y, ensayo tras ensayo, van dando forma a la escena, probando textos y acciones, realizando agregados o supresiones, siempre en función de la actuación. A veces esta actividad se prolonga después de estrenada la obra.

3. Se trata de la conocida escena de la película La quimera del oro (1926), dirigida, escrita, producida y protagonizada por Charles Chaplin. 
La potencia de las imágenes generadas radica en que la producción de sentido actoral siempre trae algo del pasado al presente, fragmentos cargados de sentido sobre los cuales la actuación emite su opinión de manera irónica y apasionada y con los cuales el director productor realiza su montaje. Y en ese acto, irónico y apasionado, directores y actores productores opinan sobre la propia actuación y sobre la escena en su conjunto.

\section{La dramaturgia de Sergio Boris como director productor}

Si tuviéramos que definir la dramaturgia de Sergio Boris, podríamos decir que se trata de una "dramaturgia de dirección". Frente a la pregunta acerca de cuál es el punto del cual parte para desarrollar su dramaturgia, encontramos en primer lugar una respuesta negativa: no lo hace de un texto dramático elaborado previamente. Partir de un texto escrito previamente significaría someter las potencias de la actuación a una lógica externa a ellas, a una "métrica" literaria (el concepto es del propio Boris) que somete a la actuación a otros ritmos, le impone tonos y temporalidades ajenos a ella.

Es cierto que la dramaturgia que Boris (2021) denomina "de escritorio" puede partir de una hipótesis de actuación: hay textos dramáticos que han sido evidentemente pensados para que los interpreten determinados actores y esto ocurre tanto en las formas realistas (por ejemplo, personajes diseñados por Roberto Cossa para ser interpretados por Luis Brandoni o Pepe Soriano) como populares (obras escritas "a medida" para Florencio Parravicini o Luis Arata por autores como Enrique García Velloso o Armando Discépolo). Incluso la llamada "producción de sentido actoral" ha hecho posible la emergencia de un tipo particular de autor capaz de incorporar procedimientos actorales asociados a actores puntuales, pero también gestos, silencios y tonos a la propia escritura: tal sería, por ejemplo, el caso particular de ciertas obras de Rafael Spregelburd, que exigen la actuación de Andrea Garrote, Javier Drolas o Héctor Díaz para su adecuada plasmación escénica. Se trata de producciones que en términos de Boris (2021) encontrarían en la ironía o el cinismo (en última instancia formas del juicio) el modo de alejarse de las formas explicativas. Hay en ellas un excedente que tiene que ver con desarrollos teóricos o matemáticos que desplazan la explicación hacia otras zonas y que necesitan muchas veces del diseño de dispositivos escénicos que vuelvan visible lo enunciado. De este modo, el espacio se vuelve correlato de la idea y se aleja de los aspectos específicamente actorales que encuentra en la ironía y el cinismo señalados por Boris y plasmados en la escritura el hilo tenue que da unidad al todo. Más allá de la mayor o menor maestría que se desarrolla en esta modalidad, no es este el camino que elige la dramaturgia de dirección de Boris.

Tampoco "dramaturgia de dirección" es para Boris partir de un texto previo desarrollando sus contenidos implícitos, estilizándolos, parodiándolos o confrontándolos polémicamente con contenidos ajenos a él a fin de producir nuevas derivas. Desde su perspectiva, lo literario siempre impone su métrica por sobre la métrica actoral y esto ocurre no sólo en los casos en que los directores productores parten de textos dramáticos sino también en los casos en que el punto de partida es un texto literario no teatral. En ese punto, la dramaturgia directorial de Boris se distancia no sólo de las formas más tradicionales de concebir y de hacer teatro sino también de formas teatrales incluidas en la denominada por Catalán "producción de sentido actoral", se aleja por ejemplo de Ricardo Bartis, quien le otorga a los textos literarios y teatrales un lugar central tanto en sus producciones escénicas como en sus clases, siempre partiendo de la idea de "robar", de robarle a la literatura (ya sea a Shakesperare, Florencio Sánchez, Roberto Arlt o Armando Discépolo), mezclando lo literario con otros discursos sociales y con formas significativas dentro de nuestro campo cultural y político (las formas populares de actuación, el tango, la glosa, el peronismo, la deuda, el box, las relaciones entre 
hombres, entre muchas otras). De esta concepción (que en Bartis aparece materializada en Postales Argentinas, en la figura del poeta que solo puede repetir textos robados), Boris conserva la idea del "robar" pero ya no se trataría de robarle a la literatura sino de "robar de lo social". En palabras del propio Boris (2020):

Incluso hay algo muy en común en las demás obras, que es un trabajo en ir al lugar, hay cierta referencia con el relato social, con esa referencia del relato social ahívamos para robar, para robar oralidad, para robar energías, frases, formas de hablar, tanto en La bohemia que fuimos a la biblioteca argentina de ciegos, en El sabor de la derrota fuimos al campo, a Uribelarrea, gente que cría chanchos, y después en Viejo solo y puto hablamos con travestis, estuvimos con travestis hablando, con farmacéuticos, visitadores médicos, lo mismo en Artaud con lo del Borda, fuimos al Borda, con los médicos, gracias a una relación que Pipi tenía con este médico, y todo eso no es para hacer un trabajo antropológico, ni tener un respeto por la referencia social sino para robar signos, como parte de la ensalada que puede estimular, porque en definitiva todo es para estimular lo que está en juego ahí en términos de vínculos expresivos, vínculos actorales, el desarrollo los vínculos expresivos, de los actorespersonajes, porque es a la vez ¿no?, uno nunca deja de ver al actor, uno ve el actor y ve al personaje al mismo tiempo, por eso el relato nunca puede dejar de ser teatral más allá incluso, de ganar y trabajar una cierta teatralidad que vaya más allá del cuento ficcional, de lo que está en juego en término de cuento, como que se abre y se expande a un relato mucho más grande.

Estas dos modalidades del "robar" (de lo literario o de lo social) resultan fundamentales a la hora de desarrollar ese otro aspecto que acompaña y canaliza el aspecto vincular: la circunstancia, es decir en qué universo (en qué espacio, con qué tonos, con que corporalidad, con qué lenguaje) se van a desarrollar los ensayos y la escena resultante. Habría que analizar entonces cuáles son las implicancias de cada una de estas modalidades.

En el trabajo citado, Catalán va a referirse a las posibles dependencias de sentidos exteriores que legitimen la actuación: estos sentidos pueden remitir a un referente textual, temático o conceptual o responder a una voluntad extraescénica que le imprimiría a la puesta un carácter coreográfico, "poético" o conceptual. Frente a estas posibilidades, el actor y el director no representativos deben evitar ceder a la aparición de sentidos trascendente o a las desviaciones puestísicas. Si tomamos el caso de Ricardo Bartis, encontramos todavía un resabio metafórico, literario, que liga su producción con textos y sentidos diseminados en nuestra tradición cultural y en la tradición cultural universal, por más que, tal como afirma Horacio González, "ofrende" esos textos y esos sentidos a la "potencia de la actuación". La elección no fortuita de esos textos y su mirada sobre ellos buscan poner en primer plano cuestiones trascendentes que son centrales para pensar nuestra cultura, nuestro pasado y nuestro presente, lo que Bartis llama "movilización de fuerzas inasibles de lo real". Así, el sacrificio artaudiano del joven cuerpo andrógino del protagonista de El corte y la metáfora del país como carnicería (con clara intertextualidad de El matadero) y del frigorífico como espacio en el que la memoria se congela, no pueden pensarse por fuera de una cierta idea de trascendencia y aún de representación, entendida en el sentido que le da Horacio González al referirse al teatro de Bartis, "no como ideal normativo, que implica un horizonte de actualización de una realidad ajena, que existe como canon del que se extrae el impulso de la representación" sino como un acto relativamente autónomo "que no emerge por comparación, contraste o interpretación de un texto previo que le serviría de modelo". Es decir: si bien la autonomía de la actuación explica parcialmente la poética de Bartis, no logra agotarla por completo en la medida en que esta se articula con tradiciones y sentidos que emergen de ella misma pero también del imaginario bartisiano que le confiere un sentido trascendente al todo, por difuso que este sentido sea. 
El teatro de Boris presenta, en relación con el teatro de Bartis, determinadas peculiaridades que es nuestro propósito relevar. En primer lugar, hay en él una "voluntad de realismo" que está ausente en Bartis y que tiene por finalidad evitar esa métrica literaria que somete al actor y eludir toda forma de trascendencia (que siempre está presente en los textos teatrales y literarios, en su métrica y sus tonos). Con "voluntad de realismo" no queremos decir de ningún modo que su teatro sea realista, sino simplemente referirnos a esa voluntad que se pone de manifiesto, por ejemplo, en la necesidad de conocer de manera directa el "referente" de sus obras. Boris y sus actores necesitan conectarse con el referente de sus producciones. Así, tal como lo enuncia el propio Boris en el fragmento citado, para la realización de La bohemia, obra que se desarrolla en una biblioteca para ciegos, van a visitar una biblioteca para ciegos; para El saborde la derrota, se ponen en contacto con el universo rural que allí se representa (y no, por ejemplo, con una vasta tradición literaria gauchesca y nativista, que de todos modos se hace presente); para Viejo, solo y puto, visitan una farmacia del conurbano bonaerense a la que los travestis van a inyectarse hormonas.

Esa "voluntad de realismo" encuentra su correlato "dramatúrgico" en la apelación a una serie de procedimientos realistas que se incluyen sin ningún tipo de voluntad paródica (como puede ocurrir en Spregelburd) y sin intención alguna de explorar los límites de un realismo perimido (como en el caso de las puestas de autores modernos que realizan Veronese o Ciro Zorzoli, este último reforzando los aspectos paródicos). Su uso de procedimientos propios del realismo es genuino, lo cual revela que su producción ya no se enmarca en ese momento en el cual era necesario polemizar con toda forma realista. Así, su obra se estructura sin prejuicios en la alternancia entre la trivialidad deliberada y el encuentro personal con algunas salvedades: lo trivial se desarrolla en ámbitos y situaciones que nunca pueden ser triviales, al menos no para el espectador de clase media que va a ver esas obras (una biblioteca para ciegos, un espacio rural degradado, la previa antes de ir a un boliche en una farmacia del conurbano a la que los travestis van a inyectarse hormonas). Sin embargo, en ninguna de estas situaciones hay un afán por conectar con sentidos trascendentes: basta comparar a los travestis de Viejo solo y puto con el "travestismo psíquico" que incluye Bartis en El pecado que no se puede nombrar, como metáfora del "travestismo político" que en palabras del propio Bartis caracteriza a la política argentina en general y a la década del noventa en particular. O comparar la carnicería y el universo rural que en Bartis son metáfora del país, con la farmacia de Boris, que no es metáfora de nada ni persigue ningún sentido trascendente. Es decir, la trivialidad que no puede ser trivial para el espectador de clase media sí es trivial para quienes se encuentran "puertas adentro". Lo peculiar del caso, es que la trivialidad realista persigue, por lo general, el fin de poner en evidencia la peligrosa banalidad de la clase media, sus prejuicios, sus lugares comunes, todo aquello que le impide realizarse como clase (se inscribe en la lógica del juicio) mientras que en Viejo, solo y puto no habría en principio un "para qué" que trascienda la pura exhibición de unos vínculos que, por otra parte, no pueden asirse a partir de la pura palabra, porque en verdad no descansan en la palabra (emite opinión desde un perspectivismo no judicativo). De hecho, la lectura del "guion" de la puesta es una empresa casi imposible ya que esos textos sólo funcionan acompañados de la acción, del gesto, de la proxemia y de los tonos de los actores y ni siquiera así pueden ser comprendidos en su totalidad: en Viejo, solo y puto prima el murmullo, el hablar en una media lengua, la palabra superpuesta, lo que el propio Boris (2020) denomina "colchón sonoro". Lo mismo vale para los encuentros personales; es difícil saber con precisión qué es lo que está en juego, por qué se producen las discusiones, las peleas que hacia el final llegan al enfrentamiento físico, pero al mismo tiempo lo que ocurre se presenta con una claridad ejemplar. Porque lo que siempre vemos es el flujo del deseo: dicho de otro modo, vemos cómo el deseo (deseo que es real, que habla de un deseo real de actores que expanden sus cuerpos en el campo de la actuación) fluye entre esos actores que no componen un personaje sino que acontecen en escena, 
permitiendo que la composición de personajes abra lugar a la composición de los cuerpos que componen "lo histriónico" que, según Boris (2021), "está en el tiempo, en el espacio y se sitúa en los cuerpos actorales en su vinculación que permiten que haya una escena, un relato amplio y mayor". Así, la alternancia entre los encuentros personales y la trivialidad deliberada no persigue otro fin que diseñar un mapa del deseo. Lo mismo vale para otros aspectos realistas como la inclusión de moderadas pero no desdeñables referencias al pasado de los personajes o la causalidad explícita que están ahí para mostrar un vínculo:

Sandra: Vamos a ir al Mágico, los tres, nos vamos a ir a bailar los tres con Yuliana y si la tengo que traer con la boca partida, la voy a traer, la voy a ayudar, voy estar con ella, porque vos no tenés ni idea lo que ella me cuidó, lo que estuvo conmigo, lo que me ayudó, ni idea.

Es decir, el diseño de un mapa del deseo resulta incompatible con cualquier forma de trascendencia: por eso no hay ni puede haber una tesis realista. La presencia de una tesis necesita de altos niveles de territorialización que resultarían incompatibles con la propuesta de Boris que se mueve, muchas veces, en el estrecho borde que separa la parodia de algún sentido trascendente sin caer ni en uno ni en otro abismo. Por eso el énfasis que se ve en las obras y que el propio Boris (2021) enuncia en la entrevista de que "el final nunca debe ser con encuentro" porque ello implica "optar por el bien" y para él "se avanza desde el mal, lo negativo; el bien es lo que hay que romper".

Así como se destierra todo vestigio de trascendencia, también hay en Boris un especial énfasis en limitar al máximo el elemento paródico (aspecto que también aparece en la evolución del teatro de Bartis pero de manera no tan marcada). Si comparamos Viejo, solo y puto con La bohemia, vemos que en esta última había aún un marcado elemento paródico que buscaba señalar la distancia entre la forma nueva y la forma desplazada pero también la distancia entre el público y el universo escénico. En Viejo, solo y puto son pocos los momentos en lo que esto sucede: lo vemos por ejemplo cuando Evaristo brinda, con la pizza en la mano "por la venta libre, por la ley de genéricos..." (lo cual produce la risa del público, entre distanciada y cómplice) y, luego, sin solución de continuidad: “...por el título, che” (lo cual produce una derivación casi sin transición a lo sentimental, al amor fraternal). $\mathrm{O}$ en los momentos en que Claudio, el visitador médico exhibe su saber específico, haciendo gala de superioridad:

Sandra: no me regala nada, me tengo que comprar yo solita. Cómo me dijiste el nombre de ese que me mostraste los folletos?

Claudio: Literatura se dice.

Sandra: Bueno, literatura, esos, los folletos

Claudio: Trípticos o dípticos, depende de cómo esté armado... folletos es lo que te dan en la calle.

Y después:

Claudio: Soy en la cadena el primero que conoce el producto, represento al laboratorio, querida y la venta se la hago a profesionales, sabés lo que es eso?

4. Se trata de dos concepciones absolutamente opuestas del componer, la primera asociada históricamente al acto creativo de actores y directores productores, la segunda a una concepción spinoziana en la que componer significa afectar y dejarse afectar positivamente y actuar como resultado de esa afección. 
Sabés lo que hay que saber? Yo no le vendo al cliente, al común que no tiene la más puta idea de lo que toma, lo nuestro es venta indirecta, in-di-recta, al médico, al farmacéutico le vendo, dejá, por favor.

Este resto paródico aparece de manera lateral y aleja momentáneamente al espectador de un mundo que se presenta como absolutamente cerrado. Lo que es importante destacar es que ni la parodia ni los procedimientos realistas enumerados contienen a la obra, más bien forman parte de su contenido: tanto la parodia como el realismo están subordinados al devenir de los cuerpos en escena; la representación está subordinada al acontecimiento o, parafraseando las palabras ya citadas de Horacio Gonzalez, es ofrendada a la potencia de la actuación, al relato que la actuación genera en relación con el tiempo y el espacio.

A partir de lo desarrollado, nos preguntamos qué sería entonces dramaturgia para Sergio Boris. Tomando parcialmente sus palabras, podemos decir que dramaturgia sería el ordenamiento espacio temporal de lo que acontece en la forma de un relato integrado por series de relatos superpuestas. Se trata de una concepción que comparte con otros creadores pero que en él toma características particulares que desarrollamos parcialmente en este trabajo. Partiendo de esta primera aproximación, vemos que para Boris la dirección tiene a su cargo fundamentalmente dos tareas: propiciar el acontecimiento y realizar una tarea de montaje que incluye agregados y supresiones. La materia con la que trabaja no es entonces la palabra aislada sino la totalidad de los elementos que la escena va proporcionando en su devenir, algunos de los cuales se obtienen "robando de lo social" y otros del modo en que los cuerpos se van vinculando en el tiempo y el espacio.

Si tuviéramos que ubicar los acontecimientos en una serie, podemos decir que lo primero que acontece es, en palabras de Boris, lo vincular asociado a una circunstancia, una "hipótesis de vínculo" que puede ser previa a los ensayos o posterior a su inicio. Que una "hipótesis de vínculo" funcione posee para él un carácter milagroso que "produce maquinaria de improvisaciones, de situaciones y de entramado de relatos" (2021). En el despliegue de las improvisaciones y situaciones en el tiempo, se va descubriendo un relato teatral que no está solo hecho de palabras: aunque las palabras se van registrando y van armando una suerte de guión, la dramaturgia del director se centra en la investigación del hecho escénico entendido como "un trabajo en el que los cuerpos actorales se vinculan en un espacio y un tiempo determinados" (Boris, 2021). Se trata de cuerpos que afectan y se dejan afectar por otros cuerpos, por el espacio que se va configurando en los ensayos y por la palabra del director y de la asistencia de dirección. En la prolongación temporal de estos encuentros, la dirección va encontrando relatos y desarrollando una escritura que, avanzados los ensayos, comienza a fijar determinados momentos y situaciones, a establecer acuerdos textuales y a definir qué es lo que se va a relatar. A ese relato o relatos que la dirección va construyendo se llega recuperando momentos de "intensidades explosivas" (Boris, 2021) pero también renunciando a ellos si los relatos que se van armando así lo exigen. Se trata de "escribir desde la dirección" sin convertirse en lo que él mismo llama un "súbdito del ensayo" (2021). Este aspecto resulta fundamental, ya que habla del modo en que a lo largo de los ensayos se distribuye el poder. Aunque la dirección tenga a su cargo ciertas tareas de montaje, de lo que se trata es de evitar que cualquiera de las instancias que intervienen en la escena subordinen a las otras a fin de que cada una de ellas pueda desplegar al máximo sus potencias sin someter a las demás. Se trata de un pensamiento que vuelve todo el tiempo en Boris en relación, por ejemplo, con el espacio: "para que el espacio no sea servil, cuando se produce, cuando se escribe desde la dirección, debe emerger de un intercambio profundo con la actuación en busca de lo desconocido de la escena, del encuentro con lo desconocido" (2021). 
Queda pendiente un trabajo acerca de las implicancias éticas y políticas del teatro de Sergio Boris. Aventuramos en este sentido los dos aspectos fundamentales en los cuales radicaría su potencia: 1) su renuncia a toda forma de vasallaje que hace posible el despliegue de las potencias contenidas de cada uno de los que intervienen en el proceso de "producción de obra" a partir del desarrollo de los vínculos y 2) su capacidad para generar acontecimiento escénico y de producir relato a partir de ese acontecimiento, sin caer en la lógica del enemigo que quiere entristecernos y reducirnos a través del juicio. Se trata de dos aspectos que se parecen bastante a una revolución. Menor seguramente, pero revolución al fin y al cabo. 


\section{Q Bibliografía}

» Bartís, R. (2003). Cancha con niebla. Teatro perdido: Fragmentos. Buenos Aires: Atuel.

"Benjamin, W. (1991). "La enseñanza de lo semejante”. Walter Benjamin. Para una crítica de la violencia y otros ensayos. Iluminaciones IV. (85-89). Madrid: Alfaguara.

»Benjamin, W. (2002). “El autor como productor”. Walter Benjamin, Ensayos. Tomo V. Madrid: Editora Nacional, 111-129.

» Boris, S. (2020). Entrevista inédita realizada por Martín Rodríguez, Leilén Araudo, Carla Pessolano, Rocío Celeste Fernández y Juan Cruz Forgnone.

»Boris, S. (2021). Entrevista inédita realizada por Martín Rodríguez.

»Catalán, A. (2002). “Producción de sentido actoral”. Teatro XXI, 12 (15-20).

»Deleuze, G. (2008). En medio de Spinoza. Buenos Aires: Cactus.

"Ferreyra, S. (2019). Estética de lo inefable. Hacia una genealogía materialista del teatro argentino. Los Polvorines: Universidad Nacional de General Sarmiento.

"Ferreyra. S., Rodríguez, M. (2020). "El actor como productor: hacia un análisis materialista de la actuación en Buenos Aires". Apuntes de teatro, 143 (42-56). 